
\title{
R Research Soure \\ Psychological suffering, medicalization and women: a perspective of Institutional Ethnography
}

\section{Luciana Fernandes Medeiros}

Universidade Federal do Rio Grande do Norte

Renata Meira Veras ( $\nabla$ renata.veras@ufba.br)

Universidade Federal da Bahia https://orcid.org/0000-0002-1681-1401

\section{Loyanne Monyk Torres Costa}

Universidade Federal do Rio Grande do Norte

\section{Gisely da Costa Araujo}

Universidade Federal do Rio Grande do Norte

Isabelly Cristina Soares Oliveira

Universidade Federal do Rio Grande do Norte

\section{Research article}

Keywords: Psychological suffering, Medicalization, Institutional Ethnography

Posted Date: March 5th, 2020

DOI: https://doi.org/10.21203/rs.3.rs-16253/v1

License: (c) (1) This work is licensed under a Creative Commons Attribution 4.0 International License. Read Full License 


\section{Abstract}

Background Recent years have seen a growing psychological suffer in women attended in primary health care in developing countries. This paper aims to analyze the psychological suffering in a small city in northeastern Brazil and its relationship with medicalization from the perspective of Institutional Ethnography (IE).

Methods We applied 202 SRQ-20 questionnaires in the first research step. In the second step, four women were interviewed in the primary health care service.

Results The results demonstrated a high number of primary health care users in psychological suffering $(47.02 \%)$. The data also point to a significant prevalence of women in psychological suffering, the use of medicines and the struggles in dealing with the difficulties of everyday life.

Conclusions The medicalization of psychological suffering appeared several times in this study through the invisibility of these sufferings under the blanket of biomedical and medicalizing discourse. Those facts can affect contemporary women and the contradictions of being a woman in a capitalist and patriarchal society.

\section{Introduction}

In the literature about psychological suffering in public health, the use of the term "common mental disorders" (CMD) is also known as minor psychiatric disorders, which represent the least severe and most frequent mental disorder (Tofoli, 2006). According to several studies (Parreira et al, 2017; Portugal et al., 2016; Pinho \& Araújo, 2012; Goldberg \& Huxley, 1992), CMD include non-psychotic depression, anxiety and somatoform symptoms, with common symptoms such as: insomnia, fatigue, forgetfulness, irritability, concentration difficulties, different somatic complaints and feelings of low self-esteem, useless, sadness.

The CMD can generate suffering and also can decrease the quality of life of affected people. It also has causes economic burden in society, mainly due to the indirect costs related to absenteeism due to disease (Portugal et al., 2016). In addition, depressive symptoms may act in comorbidity with other chronic diseases such as heart problems, diabetes and cancer (Soegaard, 2012).

The subject of psychological suffering has been studied by some researchers (Medeiros, 2003; TraversoYépez \& Medeiros, 2005; Azevedo, 2010; Azevedo, 2014; Fernandes \& Sanz, 2016). The CMD has a lack of a corresponding organic etiology. However, in accordance with the contemporary perspective of the biomedical model to be legitimized as disease, most people with suffering symptoms seek health services looking for medications, mainly anxiolytics. Consequently, the health professionals themselves became unable to develop other health care practices, as long as patients just look for medications in the health services (Azevedo, 2014). 
Thus, the present study aimed to analyze the level of the psychological suffering in a small city in the northeast of Brazil and its relation with medicalization and also investigated how the woman deal with this suffering from the Institutional Ethnography (IE) perspective.

\section{Methodological Procedures}

\section{Field research}

This is a descriptive and exploratory research based on theoretical-methodological perspective of Institutional Ethnography (IE) that is better explained in the next item. It was developed at 3 Basic Health Units in Santa Cruz, Rio Grande do Norte, Brazil. For a characterization of the psychological suffering, the study was carried out in two steps: 1) application of Self Reporting Questionnaire (SRQ-20) and informal conversation about psychological suffering during its filling and 2) in-depth interviews with four participant women. The first step sought to identify the occurrence of psychological suffering in adults between 18 and 65 years, residents in Santa Cruz/RN/Brazil. This step was performed throughout the year of 2017 and we applied 202 questionnaires. In 2018 we developed the second step of this research when we aimed to analyze how people deal with psychological suffering interviewing 4 women in this situation.

The SRQ-20 is a questionnaire for the identification of mental health problems in primary health care, validated in Brazil and recommended by the World Health Organization (WHO), especially in developing countries, because it meets the above criteria in terms of ease of use and reduced cost. The SRQ-20 (version in which the 20 questions for screening for nonpsychotic disorders are used) has been used in several countries of different cultures for screening for nonpsychotic disorders (Harding et al, 1980; Reeler \& Immerman, 1994). It brings 20 questions with answers "Yes" or "No", covering the different dimensions of psychological suffering. The answers are based on the last 30 days and the final result varies from 0 to 20 , since each "Yes" is assigned a point (Fiorott et al., 2010). If the participant reaches seven points or more, he/she probably is, at that time, in psychological suffering.

The questionnaire was applied by students who are properly trained. Respondents, before answering the 20 questions of the questionnaire, signed a Written Informed Consent Form (WICF), which reported the research objectives, as well as the risks and benefits. Those interviewed also read and signed the WICF. The research was approved by the Research Ethics Committee of Facisa/UFRN under Protocol number 2017937.

As the SRQ-20 is an instrument for screening, not diagnosis, the determination of the cut-off point for case detection, with its sensitivity and specificity, needs to be done by comparison with the gold standard, ie, standardized psychiatric interview (Gonçalves, Stein, Kapczinski, 2008). 
For this reason, it was considered important to analyze the informal conversations held during the application of the questionnaire. Thus, in the second stage of the research, the observations and interviews were analyzed based on theoretical-methodological perspective of Institutional Ethnography.

2. Institutional Ethnography (IE) as a way to understand and analyze health practices in everyday life

The Institutional Ethnography (IE) is a theoretical-methodological perspective systematized by Canadian sociologist Dorothy Smith (Smith, 2005) that has been used by some researchers in recent years to understand the actions developed in various institutions (DeVault \& McCoy, 2002; Veras, 2014).

Smith (2005) began her journey with the goal of developing a sociology for women and, therefore, a sociology for people. In this sense, the IE takes as theoretical and epistemological basis some currents of the social sciences such as symbolic interactionism and Ethnometodology, Marxist and Foucaultian thinking, as well as philosophical ideas based on phenomenology (DeVault \& McCoy, 2002; Smith, 2005; Campbell \& Gregor, 2002). With this set of assumptions, the IE has a theoretical-epistemological basis that seeks to value and understand "the point of view of the people effectively involved in the events in question seeking to enable them to understand their everyday practices as part of broader social relations in which they are inserted" (Pinheiro, 2014, p. 17).

The main concepts of the IE are: texts, ruling relations and institutions. That is, it seeks to explain why people act in a certain way in a certain place (Fernandes \& Sanz, 2016; Azevedo, 2014; Veras, 2014). The texts are the socially instituted documents and discourses that are part of the repertoire of actions, behaviors and attitudes of people in a certain institution. As an example, we can mention policies (health, social assistance, education), social contracts, the routine of the place, the flowchart, the hierarchy, among others. Thus, the texts organize "our discourses and practices, since they act as key in the conjuncture between the local settings of the daily lives of people and the normalized relations" (Veras, 2011, p. 60).

Many texts go through everyday practices and some contribute to ruling relations. The ruling relations are inspired by the work of Michel Foucault and refer to relationships between people who live in a hierarchy of one over the other. These relationships are present in the speeches and everyday practices so that some speeches overlap the other and some practices are more considered or valued than others. That way, in the health institution, for example, policies, power relations between health professionals, managers and users, as well as practices that are built into everyday life contribute to work processes and ways of acting in different health care services (Smith, 2005).

According to Smith (2005) and Veras (2011), IE aims to examine an institution as a whole, mapping and evaluating how social life is organised. It takes into account the power relationships and how the worker process is activated. The analysis is always directed to new issues and perspectives that can always be object of reflection. 
Thus, understanding how to organize the work processes in the day-to-day life of the institution it is important to point out the limits and potentialities of those actions. In the case of the Brazilian public health, it was observed that, in some contexts, the official documents are valued, but the daily practice differs enough from what is stated in the texts because there are other underlying texts and also the ruling relations that permeate these actions (Azevedo, 2014; Medeiros et al. 2018; Smith, 2005).

About the analysis in IE, Azevedo (2014) asserts that the goal of the analysis is not to reach absolute truths, but describe and explain existing social relations in that context from certain positions, including the researcher himself. In this way, the knowledge is constructed from a particular look, with theoretical basis, but as a possibility, among many.

From these assumptions, the interviews of the four (04) women were analysed by reading and re-reading the transcripts, survey of topics and categories and, finally, the relationship of these topics with the existing literature on psychological suffering. One of the themes that most stood out in the process of the analysis was the medicalization of suffering. For this reason, it was considered relevant to go deeper in the following discussion.

\section{Results And Discussion}

\section{Psychological suffering in a city of Northeast Brazil: gender and medicalization}

In the study, 202 people answered the questionnaire SRQ-20 in the city of Santa Cruz/RN/Brazil. Of the respondents, $130(64 \%)$ were women and $72(36 \%)$ men. It was found that $47.02 \%$ of these people had a score greater than seven (07), that points out to a significant index of psychological suffering during the research process, which corroborates with other studies conducted in different Brazilian territories using the SRQ-20 (Gonçalves, Stein, Kapczinski, 2008; Moreira et al., 2011; Lucchese et al, 2014; Coutinho, Almeida Filho, Mari, 1999).

Our results also pointed that among 130 respondent women, (71) $54.61 \%$ had a score greater than seven. Among 72 respondent man, this rate was $33.33 \%$ (24). This results corroborate with other studies that point out the high rate of Brazilian women in suffering (Zanello, Fouad \& Costa, 2015; Costa, Dimenstein \& Leite, 2014; Costa, Ludermir, 2005). In Recife, a population study found a total prevalence of common mental disorders in primary health care of approximately 35\%. (Ludermir \& Melo Filho, 2002). In Pelotas, the prevalence of minor psychiatric disorders in primary health care was $22,7 \%$ with $17.9 \%$ among men and $26 \%$ among women. (Lima, Soares, Mari, 1999).

The SRQ-20 questionnaire has 20 questions about their everyday life. It was observed that $70,8 \%$ of answers have affirmed that they use to feel nervous, tense or worried; $48 \%$ sleep badly and feel unhappy and $46 \%$ are easily tired and easily frightened. This set of symptoms is also more prevalent in other studies (Araujo et al., 2006; Lucchese et al., 2014) 
There was also a higher rate of no responses to symptoms like daily work suffering. Although participants have demonstrated mainly symptoms as headaches, feeling nervous, being tired or finding it difficult to make decisions, the occupational occupancy was not considered a factor for the decrease in vital energy.

To better understand the life conditions of these participants, we conducted participant observations which were registered by field diaries and also deep interviews. In general, it was observed that many people come to health services with complaints of insomnia and/or anxiety asking the health care professional for a sleeping medication. It was also highlighted the use of psychotropic drugs by many participants. As the application was held in Basic Health Units, many people took the opportunity to talk with the researchers about their health condition. In this way, many participants complained about psychological symptoms and reported their life experience, full of negative situations. However, they had access only to the general practitioner and not to other health care practices.

Besides the participant observations, we conducted deep interviews with 4 women which have scored more than 7 items in the SRQ20 questionnaire. We have noticed that the interviewees tend to comment about their suffering intertwining with situations experienced and present in daily life:

There was several changes in my brain, and I have strong emotions, anger, I suffer from attacks and I faint. So it's not good that I stay in the hall where there are people. I don't like... Because I can fall anywhere, I have fallen and got injured, and my clothes shifted, revealing my body. I said I wanted that corner because I feel more protected. (Barbara, 49 years old).

There's no way of not having stress. The routine is full of it, the coexistence of two is very difficult too, the family. I deal with people who make me feel angry every day. I had thyroid problems too. After this surgery, I was very nervous. (Carla, 47 years old).

The speeches of Barbara and Carla (fictitious names) denote the experience of a daily existence that brings ill-being and suffering under various orders. Emotions, common situations in everyday life, and relationships are aspects that make these women get sick. Simões-Barbosa and Dantas-Berger (2017) have demonstrated that in the (contradictory) processes of socialization, women are educated to be emotional, dedicate themselves to the care of others and not be competitive. Contradictory to capitalist ideology, based on individualism and competition, requires objective, rational, aggressive and competitive behaviors. Thus, the daily sufferings of women can be the result of this contradiction, a constant struggle between the ideals of being a passive and emotional woman and the capitalist society.

It is evident in these three moments of research that everyday health practices seem to include the request of health care users who wish to get rid of the uncomfortable symptom(s) and the need for health professionals to address health problems.

What is implicit in this relationship is that ruling relations can happen in two moments: when the professional, supposedly the owner of the knowledge, has the power to prescribe a "blue recipe" (popular 
term for psychotropic recipe), and when the non-specialist user, but with the power to make a scandal in the service because he/she can not get the medicine, require this medication or seek another professional to satisfy it.

Parallel to this "demand" of users for medicines, most health workers know little about psychological distress, and do not feel competent enough in this area to provide other care practices (Silveira, Almeida \& Carrilho, 2019; Azevedo, 2010). Thus, Bezerra et al. (2016) state that the exacerbated consumption of medicines is related to the hegemonic and marketing social production of health, involving different actors, including: doctors, patients, pharmaceutical industry and health regulatory agencies. Therefore, drugs become socially valued and other health care practices remain invisible.

Consequently, what predominates in this context is the prescription of psychotropics due to complaints and symptoms of psychological suffering because, in this perspective, the user's demand is in the same way as the health worker's: both will get rid of the problem in the way they were induced (by the pharmaceutical industry, for example), or by how they have learned (the hegemony of the biomedical model in health education, for example).

Silveira, Almeida and Carrilho (2019) also commented that "this is revealed in the speeches that bring out the insistence of the patients to request the prescription, the threats and aggressions that victimize the professionals and the complaints about the trafficking scheme to access controlled medicines. This is where we close the cycle into which benzodiazepines initially entered: its prescription is justified by the malaise caused by social conditions (drug trafficking and crime) and ends up sustaining the same trafficking and crime" (p.118). Here, benzodiazepines are part of a context in which drug trafficking contributes to the suffering of people who, in their turn, get drugs from this same drug traffic to alleviate malaise.

When seeking health services, many users have nonspecific somatic complaints, which can lead to difficulties in the correct management of these manifestations of suffering. Thus, there is an underdiagnosis and abuse of benzodiazepines and unnecessary examinations and referrals, commonly performed by health professionals (Silveira, Almeida \& Carrilho, 2019; Souza et al, 2017). This practice is considered as medicalization of suffering, that is, any emotional, social or cultural aspect of daily life is now understood as a health problem and must be solved with medical technology. In the words of Bezerra et al. (2016), medicalization "refers to the incorporation of social, economic and existential aspects of the human condition, such as sleep, sex, food and emotions, under the domain of the medicalizable, such as diagnosis, therapy, cure, etc." (p.149).

Even though the "demand" for the medication did not appear in the speeches of the interviewees, it is evident in the interviews of two of the participants, how the medication is valued:

(...) I am stressed, I think because of college things, homesickness, this sore throat, I am taking a medicine that is really bad, and stomachache. I've been to the nutritionist and she said that maybe it 
has to do with my diet, (...) For headache, I only take little doses of a medicine that I have at home (Carla, 19 years old)

I take Rivotril and Sertralina (Barbara, 49 years old)

The participants' discourse highlighted the increasingly aggressive and naturalized medicalization of existential suffering. It is one of the most striking symptoms of this contemporary mode of health and experience of illness (Santos \& Sá, 2013). Accoording to Simões-Barbosa and Dantas-Berger (2017) "the medicalization of malaise resulting from various types of gender-based discrimination and violence that many women experience or witness - structural, institutional, ethnic-racial, urban violence, domestic, sexual, at work - has become a legitimate resource, generating what can be considered a pharmacological violence" (emphasis added, p.04).

And this pharmacological violence is made invisible by the postmodern ideals that emphasize speed, productivity, being always ready to respond to professional, social and affective demands. In the case of women, this is even more evident since social demands accentuate the feelings of unhappiness, inadequacy and frustration associated with psychic disorders (Simões-Barbosa \& Dantas-Berger, 2017).

What is heard in services on a daily basis is that health workers are generally not satisfied with working conditions and resent the demands of users, who often want only the renewal of the prescription and nothing more. In a study on benzodiazepines in another northeastern city, the authors also found this difficulty among health professionals and users (Silveira, Almeida \& Carrilho, 2019).

In the excerpt below, Josefa tells her story:

I had a long-term treatment with Dr. X and then I improved ... I took strong medicine for 5 years. I was "weaned" and I only took it at night. The symptoms disappeared with treatment. (...). Then came the loss of my mother, she died of heart attack ... At first, I acted normally, but when I realized it was real, the problems returned with the crises. I fell into depression (Josefa, 51 years old)

In this discourse of Josefa, it can be observed how situations of loss contributed to her psychological suffering. However, when she really feels the loss of her mother, instead of grief, a process that is part of life, she gets sick and demands medication. In this sense, there is a very direct relationship between the suffering of life with the illness and the consequent use of medicines.

Like Josefa, Silveira, Almeida \& Carrilho (2019) have observed that many women enter health services with widespread complaints in order to be more likely to enter the benzodiazepine cycle of dependence, as they function in a rapid medical response, alleviating these inconvenient pains. It is the socalled chemical gag (Simões-Barbosa \& Dantas-Berger, 2017). Socially and politically, women are required to assume various roles, but at the same time surreptitiously charged with maintaining a passive stance and adapting to the status quo: 
Historically, disciplining the female body has been a surprisingly durable and flexible strategy for social control, with the health system being an important ally in the exercise of these (bio) power practices (Simões-Barbosa \& Dantas-Berger, 2017, p. .06).

Josefa continues talking about her complaints:

Yes, morning and night. I use carbamazepine and carbolytic because of the discovery of bipolar disorder. Sometimes, I have a sudden behavior change. (...) but besides that, I fight a lot for myself, sometimes I avoid talking because I'm bipolar. I'm afraid that people will misinterpret when I talk. Therefore, I avoid (...) I fight for myself! (...) Imagine, you are a good worker but you lose your job in an hour, I cried a lot.

When Bezerra et al. (2016) comments that "the holder of the decision must be, in fact, the user, who, for this, must be informed about the risks and benefits of using the drug", (emphasis added, p.152), which is not what you see in Josefa's speech. There is some passivity in her speech when she says she is taking medication for a diagnosis of bipolar disorder. Have the risks and benefits of these medicines been discussed with her? Have other health care alternatives been considered? How long would she take these medications for?

Another worrying aspect is how Josefa deals with her diagnosis. She stops talking and expressing herself to others because she is "bipolar". Josefa is not a person anymore. She becomes her disease, attributed to her by some criteria (because in other contexts, her symptoms would not have this connotation). This also characterizes the medicalization of life and suffering. Her ability to fight and to assume the political confrontation of the real causes of suffering are depotentialized, in addition to maintaining a licit drug market that sustains a business branch that has not shown any commitment to the human wellness (Simões-Barbosa \& Dantas-Berger, 2017).

The texts on mental health care are unanimous in strengthening the idea that the psychosocial paradigm, which values one's autonomy, is essential for mental health care. However, in the reality of services, what is seen is the presence of contradictions between the different texts (such as health policies $\mathrm{X}$ the biomedical paradigm) and the predominance of medicalizing practices. According to Sousa, Maciel and Medeiros (2018), there is still a view anchored in the biomedical paradigm in relation to psychic suffering and mental health issues. In the conception of care in which there is a predominance of the clinical model, centered on the physician, people do not have the power to decide on their treatment, which implies lack of autonomy (Bezerra et al. 2016). Josefa would be able to exercise her autonomy, since she says she is fighting for herself. But is this being valued in her daily life?

In this sense, medicalizing practices that strengthen the exclusion of the person are very evident in the context of this research. Even health policies advocating welcoming and bonding with users of primary health care, this discourse is still very fragile in practice. Suffering is still considered eminently of biological / organic etiology and the search for the elimination of symptoms is the main goal of users as well as health professionals. 


\section{Final Considerations}

The results of this research demonstrated that there is a high number of people who have attended primary primary health care with psychological suffering. Most of them are women. Participant observations are fundamental in qualitative research, as long as the researcher can access the health care service, knows its routine and establishes relationships with workers and users, listening and participating in the actions developed. These are some of the main guidelines of $\mathrm{IE}$, which is to know the service in depth, talk to people in their own workplace, know the resolutions, principles and protocols that govern the daily life of that institution. From this experience and experience in the service, and with an attitude of openness to what comes, without so much prejudice and a priori ideas, it is possible to identify the limitations and possibilities of the context analyzed.

The researcher starts from a certain theoretical ballast to analyze a given phenomenon. An example of this is the psychological suffering itself that appears invisible to certain professional categories. Because it is not the focus of their work and not having studied that theme, the health professional does not always give importance to the user's psychic complaints. It is very common for professionals to state that the problem of this or that patient is "only psychological" and "a relaxation would go well". With this discourse permeating their practice, the professional will probably not seek to go into the users' history, nor understand their difficulties. Not because he is incompetent and inhuman, but because his understanding of psychic suffering is not part of his discourse and care practices. Psychic suffering and all its meanings and dimensions are not part of its texts.

No wonder they "created" a term to combine all diffuse symptoms so that they can standardize the diagnosis and treatment of these symptoms as the concept of common mental disorders (CMD). This concept is insufficient and its indiscriminate use can contribute to the medicalization of suffering and malaise because it categorizes in a vague diagnosis the experiences of being a woman in a still misogynistic and patriarchal context.

Thus, this professional is criticized by humanities professionals for not considering the social, economic, as well as gender issues, among others, which are related to psychological distress. Very rarely, health professionals have this kind of discussion in their background.

There is a lot of difficulty in health services that aims to promote health, prevent disease and even cure the problems of the population when the team is made up of health professionals who, most of them, had technical and biological formation, even because it is part of most pedagogical projects the in-depth study of the human body and the scientifically proven techniques of diagnosis, treatment, rehabilitation and cure.

A possible solution would be the inclusion of humanities professionals in health services. This has been done in some contexts such as the creation and development of multiprofessional residences in university hospitals, for example. But, there are other challenges: how to articulate the practices of these professionals with the daily life of a hospital? There are reports of health professionals who feel 
threatened by the presence of psychologists who will observe and criticize their practices. There are also psychologists who believe everything to be a dehumanizing process and who eventually assume the role of overseer of other professionals.

The capitalist logic also contributes to the use and abuse of medicines, strongly propagated by the pharmaceutical industry, as it promises immediate relief from troublesome symptoms. Moreover, this logic also permeates the consultation with the doctor who needs to be quick and efficient. This generates a contradiction between the capitalist logic (less time - more effectiveness) and the principles of primary health care that require welcoming and bonding (more time - greater depth). The problem is that by momentarily "relieving" what is bothering you, you take the risk of losing your psychic abilities and resources (or even learning them) to cope with life's difficulties.

Making chorus with so many other works on the subject, it is urgent to strengthen these discussions in health contexts and the search for less medicalizing care practices, aimed at health, well-being and happiness; practices that make the social problems, affecting part of the population, visible and that provide alternative ways to lead life.

\section{Declarations}

All participants of this study have signed a Written Informed Consent Form (WICF), which reported the research objectives, as well as the risks and benefits. Those interviewed also read and signed the WICF. The research was approved by the Research Ethics Committee of Facisa/UFRN under Protocol number 2017937.

We, the authors, give the consent to the publication of this article.

We assume that there is no competing interests. We did not received funding for this research.

Luciana and Renata were responsible for the study design, data analysis, writing and final review of the manuscript. Loyanne, Gisely and Isabele were responsible for applying the questionnaires and the interviews and writing the article.

\section{References}

Araújo TM, Almeida MM, Santana CC, Araújo EM, Pinho PS. [Psychological disorders among women: a comparative study between housewives and workers]. Rev Enferm UERJ. 2006;14(2):260-9. Portuguese.

Azevedo LFM. Nervos: rede de discursos e práticas de cuidado na atenção básica no município de Natal/RN. Natal, 2010. 235p. Tese (Doutorado) - Universidade Federal do Rio Grande do Norte. 
Azevedo, L.F.M. Os trabalhadores de Saúde Diante do Nervosismo: uma Perspectiva a Partir da Etnografia Institucional. Saúde \& Transformação Social / Health \& Social Change , v. 5, p. 42-49, 2014.

Bezerra, IC; Morais, JB; Paula, ML; Silva, TMR; Jorge, MSB (2016) Uso de psicofármacos na atenção psicossocial: uma análise à luz da gestão do cuidado. SAÚDE DEBATE, Rio de Janeiro, v. 40, n. 110, p. 148-161.

Campbell, M. \& Gregor, F. (2002) Mapping social relations: A primer in doing institucional etnography. Ontário/CA: Garamond Press.

Costa MGSG, Dimenstein MD, Leite JF. Condições de vida, gênero e saúde mental entre trabalhadoras rurais assentadas. Estudos de Psicologia, 2014,19(2), pp. 89-156.

Costa, AG, Ludermir, AB. Transtornos mentais comuns e apoio social: estudo em comunidade rural da Zona da Mata de Pernambuco, Brasil. Cad. Saúde Pública, 21(1): 73-79, 2005.

Coutinho ESF, Almeida Filho N, Mari JJ. Fatores de risco para morbidade psiquiátrica menor: resultados de um estudo transversal em três áreas urbanas no Brasil. Rev Psiq Clín 1999; 26(5). http:// www.hcnet.usp.br/ipq/revista

DeVault, M. L. \& McCoy, L. (2002). Institutional Ethnography, Using Interviews to Investigate Ruling Relations. In F.J.Gubrium and J.A.Holteins (Eds). Handbook of Interview Research. Thousand Oaks/London: Sage.

Fernandes, L; Sanz, P. E. Los trastornos mentales comunes y la medicalización: Una perspectiva a partir de la etnografía institucional. Revista San Gregorio , v. 12, p. 6-15, 2016.

Fiorotti, Karoline Pedroti, Rossoni, Renzo Roldi, Borges, Luiz Henrique, \& Miranda, Angélica Espinosa. (2010). Transtornos mentais comuns entre os estudantes do curso de medicina: prevalência e fatores associados. Jornal Brasileiro de Psiquiatria, 59(1), 17-23. https://dx.doi.org/10.1590/S004720852010000100003

Goldberg D, Huxley P. Common mental disorders: a bio-social model. London: Routledge; 1992.

Gonçalves DM, Stein A T, Kapczinski F. [Performance of the Self-Reporting Questionnaire as a psychiatric screening questionnaire: a comparative study with Structured Clinical Interview for DSM-IV-TR]. Cad Saúde Pública. 2008; 24(2): 380-90. Portuguese

Harding TW, De Arango MV, Baltazar J, Climent CE, Ibrahim HHA, Ladrido-Ignacio L, et al. Mental disorders in primary health care: a study of their frequency and diagnosis in four developing countries. Psychol Med 1980; 10:231-41.

Lima MS, Soares BGO, Mari JJ. Saúde e doença mental em Pelotas, RS: dados de um estudo populacional. Rev Psiq Clín 1999; 26(5). http://www. hcnet.usp.br/ipq/revista 
Lucchese, R, Sousa, K, Bonfin, SP, Veras, I, Santana, FR. Prevalência de transtorno mental comum na atenção primária. Acta Paulista de Enfermagem, 2014; 27(3): 200-207.

Ludermir AB, Melo Filho DA. Condições de vida e estrutura ocupacional associadas a transtornos mentais comuns. Rev Saúde Pública 2002; 36:213-21.

Medeiros LF (2003) Sofrimento solitário, mal-estar compartilhado: Um estudo sobre a doença dos nervos - Dissertação de Mestrado não publicada/PPgPsi/UFRN.

Medeiros, LF; Oliveira, IC; Costa. LMT; Chagas, ABO; Carvalho, LDR; Araújo, SCM; Brito, ILS; Maia, JBS; Medeiros, MWSB (2018). Relatório final da pesquisa "mapeamento dos transtornos mentais comuns em Santa Cruz/RN/Brasil”. Não publicado. Facisa/UFRN.

Moreira JK, Bandeira M; Cardoso CS; Scalon JD. [Prevalence of common mental disorders in the population attended by the Family Health Program]. J Bras Psiquiatr. 2011;60(3):221-6. Portuguese.

Parreira BDM, Goulart BF, Haas VJ, Silva SR, Monteiro JCS, Gomes-Sponholz FA. Common mental disorders and associated factors: a study of women from a rural area. Rev Esc Enferm USP. 2017

Pinheiro, VS. (2014) A etnografia institucional: notas teóricas introdutórias. In RM Veras, RM (org.) (2014) Introdução à etnografia institucional: mapeando as práticas na assistência à saúde. Salvador: EDUFBA.

Pinho, Paloma de Sousa, \& Araújo, Tânia Maria de. (2012). Associação entre sobrecarga doméstica e transtornos mentais comuns em mulheres. Revista Brasileira de Epidemiologia, 15(3), 560-572.

Portugal, Flávia Batista, Campos, Mônica Rodrigues, Gonçalves, Daniel Almeida, Mari, Jair de Jesus, \& Fortes, Sandra Lúcia Correia Lima. (2016). Qualidade de vida em pacientes da atenção primária do Rio de Janeiro e São Paulo, Brasil: associações com eventos de vida produtores de estresse e saúde mental. Ciência \& Saúde Coletiva, 21(2), 497-508.

Reeler AP, Immerman R. A preliminary investigation into psychological disorders among Mozambican refugees: prevalence and clinical features. Cent Afr J Med 1994; 40:309-15.

Silveira, LC; Almeida, AN; Carrilho, C. (2019) Os benzodiazepínicos na ordem dos discursos: de objeto da ciência a objeto gadget do capitalismo. Saúde Soc. São Paulo, v.28, n.1, p.107-120.

Simões-Barbosa, Regina Helena ; Dantas-Berger, Sônia Maria (2017) Abuso de drogas e transtornos alimentares entre mulheres: sintomas de um mal-estar de gênero? Cad. Saúde Pública, 33(1), p.01-11.

Smith, D. (2005) Institutional ethnography - A sociology for people. New York: Altamira Press.

Soegaard, H. J. (2012). Undetected CommonMen- tal Disorders in Long-TermSickness Absence. International Journal of Family Medicine, 2012(474989). doi:10.1155/2012/474989. 
Sousa, PF; Maciel, SC; Medeiros, KT. Paradigma Biomédico X Psicossocial: Onde são Ancoradas as Representações Sociais Acerca do Sofrimento Psíquico? Trends Psychol., Ribeirão Preto, vol. 26, n 2, p. 883-895 - Junho/2017

Tófoli, L. F. F. Transtornos somatoformes, síndromes funcionais e sintomas físicos sem explicação. Em: A. C. Lopes (Org.), Tratado de clínica médica. São Paulo: Roca. 2006.

Traverso-Yepez, Martha; Medeiros, Luciana. (2005). The Complexity of Symptoms and Meanings Involving "Nerves" in the Brazilian Public Health System. Qualitative health research. 15. 1231-43. $10.1177 / 1049732305277858$.

Veras, RM. (2011) Etnografia institucional: conceito, usos e potencialidades em pesquisas no campo da Saúde. Sau. \& Transf. Soc., ISSN 2178-7085, Florianópolis, v.1, n.2, p.58-66.

Veras, RM (org.) (2014) Introdução à etnografia institucional: mapeando as práticas na assistência à saúde. Salvador: EDUFBA

Zanello V, Fiuza G, Costa HS. Saúde mental e gênero: facetas engendradas do sofrimento psíquico. Fractal: Revista de Psicologia, 2015, v.27, n.3, pp. 238-246.

\section{Figures}




\section{SRQ 20 Items}

Do you often have headaches?

Is your appetite poor?

Do you sleep badly?

Are you easily frightened?

Do your hands shake?

Do you feel nervous, tense or worried?

Is your digestion poor?

Do you have trouble thinking clearly?

Do you feel unhappy?

Do you cry more than usual?

Do you find it difficult to enjoy your daily activities?

Do you find it difficult to make decisions?

Is your daily work suffering?

Are you unable to play a useful part in life?

Have you lost interest in things?

Do you feel that you are a worthless person?

Has the thought of ending your life been on your mind?

Do you feel tired all the time?

Do you have uncomfortable feelings in your stomach?

Are you easily tired?

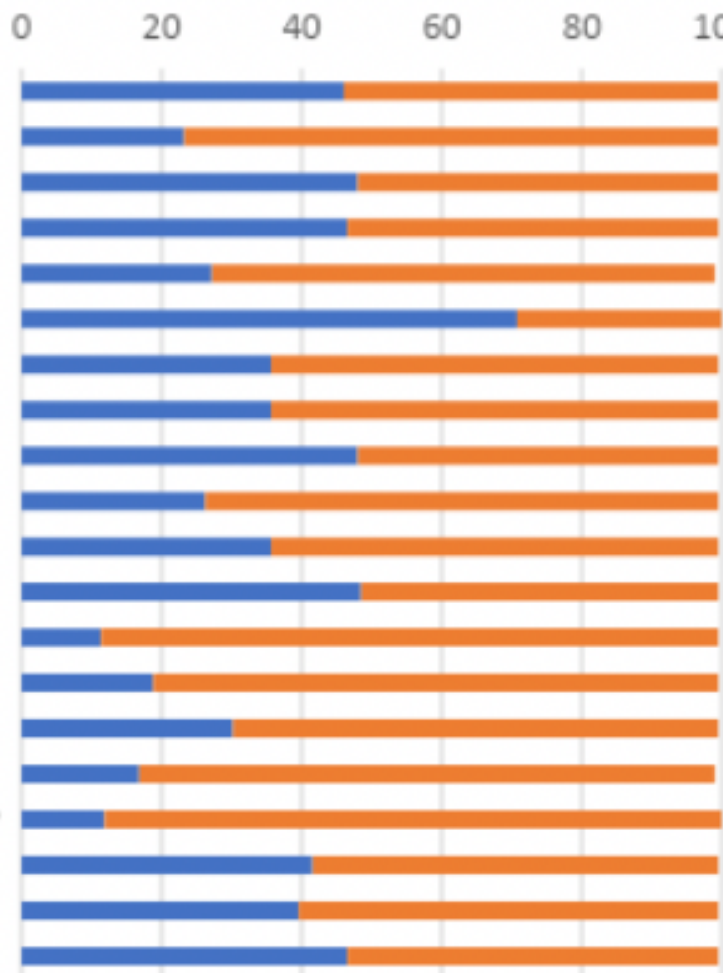

Yes $\%$ No \%

\section{Figure 1}

\section{Results of the SRQ-20 questionnaire}

